\title{
DA DISTINÇÃO ENTRE DOIS MUNDOS/NÍVEIS: UM ESTUDO SOBRE OS DOMÍNIOS SEMIÓTICO E SEMÂNTICO
}

\author{
ABOUT THE DISTINCTION BETWEEN TWO WORLDS/LEVELS: \\ A STUDY OF THE SEMIOTIC AND SEMANTIC DOMAINS
}

\begin{abstract}
RESUMO: Neste estudo, procuramos investigar o problema da significação a partir da perspectiva sobre as noções de forma e sentido na linguagem, propostas por Émile Benveniste (2006). Este trabalho justificase na medida em que busca compreender de que maneira se constroem os sentidos que circulam nas práticas enunciativas, em especial no discurso sobre o incêndio da boate Kiss, ocorrido no dia 27 de janeiro de 2013, na cidade de Santa Maria, Rio Grande do Sul, Brasil. O objetivo dessa pesquisa é analisar a maneira como os domínios do semiótico e do semântico funcionam no processo de significação da linguagem. O estudo tem como pressupostos teóricos as noções sobre forma e sentido na linguagem propostas por Émile Benveniste (2006) em sua obra Problemas de Linguística Geral II, bem como algumas considerações sobre os estudos benvenistianos discutidas por Valdir do Nascimento Flores (2013). O corpus dessa pesquisa é composto por três recortes do livro intitulado Todo dia a mesma noite, de autoria de Daniela Arbex, cuja obra tem o caráter de uma extensa reportagem sobra a tragédia na boate Kiss. A pesquisa é do tipo exploratória, bibliográfica e sua análise é qualitativa. A constatação deste trabalho é de que o domínio semântico, embora sempre relacionado e só existente por conta do domínio semiótico, se destaca por ser o responsável pela riqueza infinita de sentidos, uma vez que sempre considera o ato enunciativo como único, atualizado no presente da enunciação, e que dá margem para acréscimos de sentidos que dependem do próprio uso do sistema que é a língua.
\end{abstract}

Palavras-chave: Semiótico; Semântico; Enunciação.

\begin{abstract}
In this study, we seek to investigate the problem of meaning from the perspective about the notions of form and meaning on the language proposed by Émile Benveniste (2006). This work is justified insofar as it seeks to understand how the senses circulating in the enunciative practices are constructed, especially in the discourse on the Kiss nightclub fire, which took place on January 27, 2013, in the city of Santa Maria, Rio Grande do Sul, Brazil. The objective of this research is to analyze the manner how the semiotic and semantic domains work in the signification process of the language. The study has as theoretical presuppositions the notions about form and meaning on the language proposed by Émile Benveniste (2006) in his work Problems of General Linguistics II, as well as some considerations about the Benveniste studies discussed by Valdir do Nascimento Flores (2013). The corpus of this research is composed of three snippets from the book titled All Day the Same Night, by Daniela Arbex, whose work has the character of an extensive report on the tragedy in the Kiss nightclub. The research is exploratory, bibliographic and its analysis is qualitative. The conclusion of this work is that the semantic domain, although always related and only existing on account of the semiotic domain, stands out for being responsible for the infinite meanings wealth, since it always considers the enunciative act as unique, updated in the present of the enunciation, and it enables meanings additions that depend on the own use of the system that is the language.
\end{abstract}

Key-words: Semiotic; Semantic; Enunciation; Kiss nightclub

\footnotetext{
${ }^{1}$ Mestre em Leitura e Produção Discursiva (UPF). E-mail: brianeletras@gmail.com.

2 Doutora em Linguística (PUCRS). E-mail: claudiast@upf.br.
} 


\section{INTRODUÇÃO}

Este trabalho traz um olhar crítico sobre os sentidos que se produzem e são decorrentes das práticas enunciativas do homem na sociedade. Tal perspectiva, neste texto, leva em consideração o discurso sobre a tragédia da boate Kiss, ocorrida em 27 de janeiro de 2013, em Santa Maria, no Rio Grande do Sul. Acontecimentos traumáticos da história da sociedade costumam deixar resquícios que, não raramente, são ilustrados e encontram sua perpetuação nos acontecimentos enunciativos dos sujeitos que participaram, de alguma maneira, de tais eventos. São esses acontecimentos os objetos de nosso interesse.

Estabelecendo-se como uma espécie de extensa reportagem sobre a tragédia da boate Kiss, a obra Todo dia a mesma noite ${ }^{3}$, de Daniela Arbex, oferece a seus leitores subsídios para pensar sobre o sentido que o signo linguístico pode apresentar no momento da sua atualização, ou seja, quando enunciado, levando em consideração a Teoria da enunciação, segundo o linguista francês Émile Benveniste. Já no prefácio da obra de Arbex, Marcello Canellas traz uma reflexão cara aos estudos enunciativos, quando afirma que o significado literal de "Kiss", nome da casa noturna na qual ocorreu a tragédia, se esvaziou de sentido, e que "tragédias são episódios tão avassaladoramente desconstrutivos da rotina esperada, tão perturbadoramente desarrumadores da ordem natural, tão violentamente instauradores da ruína e do caos, que nem mesmo a semântica se mantém em pé" (ARBEX, 2018, p. 7). Este trabalho procura, justamente, entender as relações entre os domínios do semiótico e do semântico ${ }^{4}$, na tentativa de compreender como esses dois modos de leitura da significação interferem na construção dos sentidos.

Com vistas às noções de forma e sentido na linguagem defendidas por Benveniste em sua obra Problemas de Linguística Geral II (2006) especificamente no texto, buscamos compreender o poder significante da língua, considerando, impreterivelmente, o presente da enunciação, ou seja a atualização do sentido. Portanto, o objetivo desta reflexão é analisar a maneira como os domínios do semiótico e do semântico funcionam no processo de significação da linguagem. O corpus deste trabalho é composto por três recortes do já mencionado livro Todo dia a mesma noite, de autoria de Daniela Arbex. Nesses recortes temos a unidade "kiss" funcionando e significando de maneiras diferentes, e é justamente esse funcionamento que nos interessa, pois ele estabelece estreita relação com as noções de forma e sentido, assim como os domínios do semiótico e do semântico, pressupostos por Benveniste, de certa maneira comprovando a diferença entre eles na prática enunciativa.

A investigação aqui proposta se organiza em dois grandes momentos. Em primeiro lugar, trazemos algumas considerações sobre os estudos de Benveniste como um todo e a maneira como seus escritos devem ser lidos, à luz dos apontamentos de um de seus estudiosos, Valdir do Nascimento Flores (2013). Ainda nesse mesmo bloco realizamos algumas discussões em torno das noções de forma e sentido propostas por Benveniste, explicando seus desenrolamentos (em especial as concepções de domínio semiótico e semântico), construindo, dessa forma, um panorama teórico como base para a análise. $\mathrm{Na}$ sequência, realizaremos a análise do corpus em questão, buscando identificar a maneira como o processo de significação se comporta na relação entre o campo do semiótico e do semântico, levando em consideração o aporte teórico estabelecido anteriormente.

\section{SOBRE OS MODOS DE SER LÍNGUA}

Estudar a língua é sempre um desafio. Tomamos como nosso objeto de estudo exatamente aquilo que nos difere de outros animais: a capacidade de colocarmos em ação um sistema de signos,

\footnotetext{
${ }^{3}$ Livro-reportagem publicado em janeiro de 2018 e escrito a partir de centenas de depoimentos de pessoas direta ou indiretamente ligadas ao incêndio da Boate Kiss, tragédia ocorrida em 2013 na cidade de Santa Maria, Rio Grande do Sul, Brasil.

4 Os estudos em torno desses diferentes níveis tiveram seu início a partir da publicação do texto A forma e o sentido na linguagem, que compõe um dos capítulos do livro Problemas de linguística geral II (1966).
} 
como diria Saussure, e com ele podermos nos expressar, pedir, reclamar, prometer, contar, viver. Ora, com tantas possibilidades e mistérios que envolvem a língua, não são poucos aqueles que se aventuraram na tentativa de decifrar a característica que nos faz seres humanos. De todas as postulações já existentes sobre a língua, para esse trabalho vamos nos debruçar sobre as considerações de Émile Benveniste.

Trabalhar com Benveniste também é sempre um desafio. Ler Benveniste é ter a certeza de que vamos nos deparar com uma obra de grande escala, cujo objetivo não seria o de explicar conceitos e métodos a serem aplicados em análises mas, antes disso, "Benveniste propõe categorias de análise, teoriza sobre elas e desenvolve as análises dentro desses limites" (FLORES, 2013, p. 29). Portanto, para a proposta de análise aqui realizada, é preciso ter em mente que cada texto de Benveniste apresenta sua própria lógica interna e que, por esse motivo, é importante ressaltar que realizaremos uma espécie de recorte teórico - para nós teórico-metodológico - para esse estudo.

O texto A forma e o sentido na linguagem compõe o capítulo 15 do Problemas de Linguística Geral II e, inicialmente, foi um texto dirigido a filósofos durante um congresso entre os anos de $1966 \mathrm{e}$ 1967. A partir das considerações desse texto, discutiremos as características dos domínios semiótico e semântico, sempre levando em consideração a organização interna desse mesmo texto, sem fazer referências a outros momentos (anteriores, por exemplo) ${ }^{5}$ do estudo de Benveniste. Porém, apesar de adotarmos essa metodologia, que requer um recorte textual para conseguirmos realizar o que aqui nos propomos, ainda assim há um modo de ver a linguagem que perpassa todo o estudo de Benveniste, e que em hipótese alguma pode ser descartado. Uma afirmação que resume, em poucas palavras, o grande pressuposto do estudioso: o homem está na língua.

Sobre o axioma de Benveniste, precisamos esclarecer que esse "[...] decorre de um princípio epistemológico: independentemente de para onde se olhe, a linguagem, entendida como intersubjetividade, é condição para que o homem exista" (FLORES, 2013, p. 43). Dessa maneira, a linguagem e o homem estão intrinsecamente imbricados nesse movimento de significação, problemática que nos é tão cara para a realização deste trabalho e que deveria estar envolvida em qualquer pesquisa que mobilizasse as considerações de Benveniste.

Dentre esses esclarecimentos realizados, é importante lembrar, também, que quando falamos em Benveniste, não raramente as considerações daquele que para nós é considerado o pai da Linguística, Ferdinand de Saussure, vêm à tona, uma vez que ler Benveniste também significa ler Saussure nas estrelinhas. Saussure é um dos poucos linguistas a quem Benveniste revela algum tributo em suas indagações. Segundo Claudine Norman, citada por Flores (2013, p. 50), a relação entre Saussure e Benveniste é uma relação de encontro. Por esse motivo, antes de encararmos a relação entre Saussure e Benveniste como uma relação de filiação, como se um apenas reproduzisse o outro, tentaremos, no desenvolvimento desse trabalho, promover uma pequena conversa entre os dois, na tentativa de esclarecer o que, para Benveniste, seriam os domínios do semiótico e do semântico.

Diante disso, apresentamos a seguir o que possibilita que essa simbiose entre homem e linguagem seja possível - a língua e seus domínios.

\subsection{O domínio semiótico: percepções sobre forma e sentido}

Estudar a língua, hoje, significa ter um mar de possibilidades e poder escolher a abordagem que se quer empregar dependendo do objetivo a ser alcançado. As teorias sobre língua e linguagem evoluíram e promoveram a expansão do seu próprio horizonte, mas nem sempre foi assim. Benveniste, em seu texto A forma e o sentido na linguagem, texto escrito em 1966, aborda a questão da forma e do sentido como linguista, mesmo que ele tenha sido produzido, em um primeiro mo-

5 BENVENISTE, E. Os níveis de análise linguística. In: Problemas de linguística geral I. Campinas: Pontes, 2005 [1962], p. 127-140. Texto de Benveniste que trata das noções de forma e sentido numa primeira elaboração.

https://periodicos.unifap.br/index.php/letras

Macapá, v. 10, n. 1, $1^{\circ}$ sem., 2020 
mento, para um debate com filósofos. Na época, os estudos que buscavam especular sobre a questão do sentido eram abominados e, na tentativa de justificar essa descrença nos estudos sobre o sentido, Benveniste postula que "de fato, as manifestações do sentido parecem tão livres, fugidias, imprevisíveis, quanto são concretos, definidos e descritíveis os aspectos da forma." (BENVENISTE, 2006, p. 221, grifos do autor).

Porém, apesar dessa primeira aparência sobre forma e sentido que um rápido e desinteressado olhar poderia causar, é preciso esclarecer algumas questões que se distanciam dessa maneira simplista de separar as duas noções. Segundo Benveniste (2013), forma e sentido podem ser consideradas noções gêmeas, mas ainda assim possuem algumas diferenças. Antes de pensarmos mais especificamente nas discrepâncias que o linguista afirma existirem, precisamos lembrar que, antes de qualquer outra formulação, a linguagem significa, e que "[...] bem antes de servir para comunicar, a linguagem serve para viver" (BENVENISTE, 2006, p. 222). Mas o que exatamente significa dizer que a linguagem serve para viver?

É fato que a linguagem detém o poder de estabelecer relações entre os indivíduos em uma sociedade. Do contrário, de que outra maneira poderíamos revelar nossos anseios, medos, preocupações e o modo como enxergamos o mundo e nos relacionamos com os sujeitos que nele vivem? A linguagem é o elo entre os indivíduos e tudo aquilo que está fora dessa relação. Por esses motivos, o problema da significação é um grande problema, já que envolve toda essa dinâmica da linguagem como meio para que um indivíduo se estabeleça como sujeito e possa, de fato, viver.

Dessa maneira, fica estabelecido que "a língua é um sistema de signos" (BENVENISTE, 2006, p. 224). Para aqueles que se debruçam sobre os estudos linguísticos, essa afirmação pode soar como plágio, uma vez que é difícil não associar tal ideia aos pressupostos de Ferdinand de Saussure. Mas, como já esclarecemos neste trabalho, levaremos em consideração a relação entre Benveniste e Saussure como uma relação de encontro, tomando emprestada a visão de Claudine Norman sobre isso.

Desse encontro, precisamos considerar o que postula o pai da linguística sobre a língua, que além de ser um sistema de signos é "[...] um produto social da faculdade de linguagem e um conjunto de convenções necessárias, adotadas pelo corpo social para permitir o exercício dessa faculdade nos indivíduos." (SAUSSURE, 2006, p. 41). Queremos, aqui, chamar a atenção para um trecho em específico da postulação de Saussure, quando ele afirma que a língua permite o exercício da faculdade da linguagem nos indivíduos. Essa afirmação nos é de essencial importância, pois aqui chegamos ao cerne das considerações desenvolvidas por Benveniste sobre o nível semiótico.

Consideramos, assim, que o sistema de signos - que é a língua - é o meio pelo qual a linguagem se revela. Dessa maneira, a língua é imprescindível para a existência da linguagem, assim como essa última pressupõe a existência da primeira. Portanto, "dizer que a língua é feita de signos é dizer antes de tudo que o signo é a unidade semiótica." (BENVENISTE, 2006, p. 224, grifos do autor). O domínio semiótico, então, tem como unidade o signo, que por sua vez, segundo Benveniste (2006), tem como critério um limite inferior, já que não se pode descer abaixo do nível do signo sem perder a propriedade de significação. Tomando, então, o signo como unidade do nível semiótico, as noções de forma e sentido estão nele incutidas no que costumamos chamar de significante e significado, duas faces indissociáveis de um mesmo conceito. Significante é "a forma sonora que condiciona e determina o significado, o aspecto formal da entidade chamada signo" (BENVENISTE, 2006, p. 225)

Assim, tudo aquilo que é do nível semiótico estabelece-se e pode ser identificado no interior da língua. Segundo Benveniste (2006), no domínio semiótico o sentido se dá pelas relações paradigmáticas, ou seja, na relação de oposição entre os outros signos. De encontro novamente com Saussure (2006), lembramos que um signo é o que o outro não é, e essa condição de diferença dá sentido ao signo. Porém, se considerarmos o axioma de Benveniste de que o homem está na língua, é imprescindível darmos atenção a outro caráter que a língua necessita: o de se realizar por meios vocais que formam palavras dotadas de sentido. É preciso pensarmos no uso do sistema de signos e em como as noções de forma e sentido se comportam nessas condições. 
Vale lembrar que não nos comunicamos por signos, e sim por frases, “[...] mesmo que truncadas, embrionárias, incompletas, mas sempre por frases” (BENVENISTE, 2006, p. 228). Porém, é errôneo pensar que a frase se limitaria a uma simples conexão de signos, como se fosse uma adição de unidades semióticas. É preciso esclarecer que "[...] o signo e a frase são dois mundos distintos e que exigem descrições distintas." (BENVENISTE, 2006, p. 229). Dessa maneira, adentramos agora no universo do domínio semântico, na tentativa de esclarecer algumas peculiaridades e seu modo de funcionamento. A seguir, trazemos uma reflexão sobre o domínio semântico.

\subsection{O domínio semântico: percepções sobre forma e sentido}

No pensar sobre as noções de forma e sentido, é importante ressaltar que essas não se limitam ao domínio semiótico, mas encontram sua própria maneira de ser no domínio semântico, uma vez que "há para a língua duas maneiras de ser língua no sentido e na forma: "[...] a língua como semiótica e [...] a língua como semântica."” (BENVENISTE, 2006, p. 229). No nível semântico temos a ocorrência de um movimento que extrapola aquilo que está dentro dos domínios do linguístico: percebemos a língua em conexão com aquilo que se encontra para além dela. Aqui, apresenta-se a principal diferença entre os dois modos de ser língua, posto que "a semiótica se caracteriza como uma propriedade da língua; a semântica resulta de uma atividade do locutor que coloca a língua em ação" (BENVENISTE, 2006, p. 230).

Esse colocar a língua em ação, de que nos fala Benveniste, pressupõe uma noção muito importante, que se apresenta transversal em todo seu estudo e que se torna essencial para o entendimento do que o linguista propõe sobre o domínio semântico: o presente da enunciação. Toda enunciação se desenvolve dentro de uma esfera que determina um aqui e um agora que são irrepetíveis. Isso significa dizer que, ainda que o enunciado possa repetir-se infinitamente, "toda forma verbal [...] está sempre ligada a um certo presente, portanto a um conjunto cada vez único de circunstâncias" (BENVENISTE, 2006, p. 230). O presente da enunciação sempre será diferente a cada ato enunciativo, tornando esse ato sempre um acontecimento novo.

Dessa maneira, precisamos pensar nas noções de forma e sentido, em relação ao domínio semântico, de um modo adverso daquele que antes propomos ao discutir sobre o nível semiótico. Enquanto no domínio semiótico tínhamos como unidade o signo, no nível semântico essa unidade passa a ser a palavra, sendo que "[...] as palavras, instrumentos da expressão semântica, são materialmente os signos do repertório semiótico.” (BENVENISTE, 2006, p. 233). Porém, é importante estarmos atentos para o fato de que, segundo Benveniste (2006), os signos são genéricos e conceptuais quando tratados na concepção semiótica (realidade intrínseca da língua), enquanto as palavras, ainda que possam ser tomadas como signos do repertório semiótico, são sempre específicas e dependentes das circunstâncias da enunciação (realidade extrínseca da língua). No nível semântico, a forma se dá por meio das relações sintagmáticas, ou seja, pela combinação de palavras no eixo sintagmático, enquanto que o sentido é, justamente, a ideia que resulta dessa sintagmatização no presente da enunciação. Mas ainda é preciso ressaltar que "a expressão semântica por excelência é a frase" (BENVENISTE, 2006, P. 229).

O linguista defende a ideia de que, quando mudamos do nível semiótico para o semântico, ocorre uma mudança radical de perspectiva. O nível semiótico não é posto de lado, mas suas noções são trazidas para a análise formando outras relações, já que o nível semântico extrapola a língua e vai tratar, também, da atividade de um locutor que emprega essa língua, que a coloca em funcionamento. De acordo com o que propõe Benveniste (2006), nos comunicamos por frases, logo, entendemos a perspectiva de que a frase seja, então, a expressão semântica por excelência. Dessa maneira, “[...] o ‘sentido' da frase está na totalidade da ideia percebida por uma compreensão global; a 'forma' se obtém pela dissociação analítica do enunciado processada até as unidades semânticas, as palavras.” (BENVENISTE, 2006, p. 232).

Quando falamos em nível semântico, portanto, falamos sempre em frases, e se nos referimos

https://periodicos.unifap.br/index.php/letras

Macapá, v. 10, n. 1, $1^{\circ}$ sem., 2020 
a frases pressupõe-se, na totalidade das possibilidades, um enunciador que emprega a língua e se enuncia, em um aqui e um agora. É esse emprego da língua que será estudado na sequência desse trabalho, por meio da análise de dois recortes do corpus em questão.

\section{OS SENTIDOS (DES)CONSTRUÍDOS}

O objetivo principal deste trabalho é o de analisar a maneira como os domínios do semiótico e do semântico funcionam no processo de significação da linguagem. Para tanto, lançamos mão de três trechos da obra Todo dia a mesma noite, de Daniela Arbex, lançado em 2018 pela editora Intrínseca e que se apresenta no formato de uma reportagem estendida, cujos recortes compõem o corpus de análise dessa pesquisa. Tais recortes serão, na sequência, nomeados de enunciados, e neles podemos observar um destacamento, indicando o foco do processo analítico.

Nosso problema a ser discutido é a significação e, dessa maneira, tomamos emprestada a ideia de Benveniste (2006), quando o estudioso postula que a linguagem, por si só, é a atividade significante por excelência. A discussão está ligada não a essa característica intrínseca da linguagem, mas à maneira como ela se desenvolve e se institui. Assim, destacamos o primeiro recorte do corpus para realizarmos alguns apontamentos.

Enunciado 1: "Em 19 de abril de 2012 foi emitido um boletim de vistoria para a renovação do Alvará de Localização em nome da boate Kiss, que, nessa data, estava com a Licença de Operação Ambiental vencida e também sem o registro de Anotação de Responsabilidade Técnica para os processos de renovação”. (ARBEX, 2018, p. 74)

É preciso notar, em primeiro lugar, que as unidades boate Kiss são destacadas no Enunciado 1. Como explicado anteriormente, isso se deve pela necessidade de darmos ênfase a essas unidades como foco do processo analítico que aqui se constrói. Nos enunciados subsequentes essa marcação aparecerá novamente, e aí teremos um ponto de comparação na nossa discussão sobre os níveis semiótico e semântico. Kiss era o nome dado à casa noturna onde a tragédia, relatada na obra de Daniela Arbex, ocorreu. Um primeiro questionamento emerge quando percebemos essa unidade como sendo, originalmente, da língua inglesa. Essa questão, como vamos perceber, não interfere de maneira alguma no processo de significação aqui estudado, pois essa unidade, ainda que de língua estrangeira, funciona em nossa língua como um substantivo próprio, que é usado para referir-se à casa noturna.

Torna-se necessário, então, lembrar que "é no uso da língua que um signo tem existência; o que não é usado não é signo, e fora do uso o signo não existe" (BENVENISTE, 2006, p. 227). A unidade Kiss, portanto, constitui-se como signo, mesmo que em língua portuguesa, pois seu uso é real e parte integrante dos processos enunciativos em nossa sociedade. Trataremos, a partir de agora, dos destaques do Enunciado 1 como sendo dois signos, boate e Kiss, já na perspectiva do domínio semiótico. Dessa maneira, esses signos apresentam as duas faces indissociáveis por natureza: um significante e um significado, sendo o primeiro o responsável por condicionar e determinar o segundo, de acordo com Benveniste (2006). O sentido desses dois signos se dá, justamente, por sua oposição aos outros signos no eixo paradigmático da língua. Logo, esses dois signos, quando tratados dentro da esfera do domínio semiótico, estabelecem-se e podem ser identificados pela língua e só por ela.

Porém, já adentrando no universo do semântico, temos a iminência da frase, que é a própria expressão semântica e que, dessa forma, pressupõe sempre um enunciador que faz o uso da língua para enunciar-se, transformando, nesse processo, a própria significação da língua. No recorte aqui analisado, temos os signos boate e Kiss (nível semiótico) que são conceptuais e genéricos, e que, por essas razões, possuem a característica de serem repetíveis infinitamente. Por outro lado, temos duas palavras (nível semântico) que, no Enunciado 1 instituem um acontecimento particular, que jamais se repetirá novamente. Isso será comprovado na sequência da análise, que agora se desenvolve a 
partir da discussão do Enunciado 2.

Enunciado 2: "Abrir os olhos e enfrentar a realidade era tão doloroso quanto perceber o corpo mutilado. Não seria nada fácil carregar o rótulo de sobrevivente. Depois da Kiss, ninguém seria mais o mesmo. Ninguém.” (ARBEX, 2018, p. 65)

No enunciado 2 percebemos novamente a unidade Kiss em funcionamento na língua. Em uma análise de nível semiótico, notamos o que antes já havia sido constatado: assim como qualquer outro signo, o signo Kiss possui duas faces indissociáveis, um significante e um significado, e o sentido desse signo se institui por essa última faceta, que se restringe unicamente a uma propriedade da língua. Porém, analisando esse mesmo signo, agora no domínio semântico, temos um acontecimento novo. O Kiss do Enunciado 1 não é o mesmo Kiss do Enunciado 2, pois cada um desses recortes se refere a diferentes presentes da enunciação.

Essa questão fica ainda mais clara quando percebemos que, analisando os dois enunciados como um todo, temos o primeiro referindo-se claramente ao lugar físico cujo nome é Kiss, a boate na qual a tragédia ocorreu, enquanto o segundo enunciado analisado, sendo um novo acontecimento enunciativo, diz respeito a todos os aspectos que envolvem a tragédia da boate Kiss e os resume em uma só palavra. Eis o poder da língua. Essa capacidade de uma palavra carregar sentidos diversos que não se excluem, mas se somam na atividade semântica, é o motivo mesmo pelo qual dizemos que o domínio semântico extrapola os limites da língua. Portanto, postula-se que "[...] o sentido de uma palavra é seu emprego" (BENVENISTE, 2006, p. 231). O sentido da palavra Kiss no Enunciado 2 institui-se pelo emprego dessa palavra nesse ato enunciativo.

Tal emprego dá à palavra Kiss o poder de carregar sentidos vários que são comprovados quando percebemos que o enunciador não sente a necessidade de pontuar por meio de marcas linguísticas todas as questões que envolvem esse acontecimento, ou seja, o incêndio, as mortes, as vítimas posteriores, a comoção da sociedade, entre outros, contentando-se em enunciar o que é preciso a partir da frase depois da Kiss. O presente da enunciação, que é único, é o responsável pela possibilidade de termos dois signos, idênticos no nível semiótico, funcionando de maneiras diferentes na língua em uso. Vamos, agora, analisar o último recorte dessa pesquisa, no intuito de realizar mais alguns apontamentos quanto à significação da língua nos níveis semiótico e semântico.

Enunciado 3: "A busca por respostas, principalmente por justiça, ainda mobiliza os parentes das vítimas em meio a uma maratona de teses, indícios e provas que compõe o caso Kiss." (ARBEX, 2018, p. 74)

No Enunciado 3, notamos o mesmo poder semântico da língua, já constatado na análise do Enunciado 2. Nosso foco de análise, nesse momento, recai sobre a frase caso Kiss, destacada no recorte. Temos, novamente, o signo Kiss funcionando como um substantivo próprio, dando nome ao caso da tragédia que, nesse momento, toma proporções judiciárias. Esse é um modo de composição linguística recorrente em acontecimentos enunciativos da esfera judiciária no Brasil. Como exemplo, podemos citar o Caso Isabella Nardoni, Caso Bernardo, Caso Richtofen, entre outros. O poder significante da língua torna-se ainda mais visível quando percebemos o quanto essa união de sentidos em uma única forma linguística é recorrente. Se analisarmos a expressão "Caso Isabella Nardoni”, por exemplo, temos o substantivo próprio que, em nível semiótico, possui um significante e um significado que são restritos à esfera da língua.

No momento que analisamos essa frase, agora fazendo referência ao domínio semântico, o substantivo próprio preenche-se de sentidos que só são possíveis de serem apreendidos se relacionados ao presente da enunciação e ao sentido todo expresso pela frase, ou seja, incluindo o uso da palavra caso antes do substantivo próprio. Tal frase não refere-se à pessoa Isabella Nardoni, mas a todos os aspectos que fazem referência ao seu homicídio, a revolta da família, a comoção do país, a investigação policial, as motivações do crime, etc. 
Da mesma maneira, o caso Kiss, se tomado como frase dentro do domínio semântico, ganha sentidos antes não comportados pela palavra Kiss, o que é justificado pela teoria de Benveniste do aqui e agora, de acontecimentos enunciativos sempre novos, já que "é como consequência de sua coaptação que as palavras contraem valores que em si mesmas elas não possuíam e que são até mesmo contraditórios com aqueles que elas possuem em outros lugares" (BENVENISTE, 2006, p. 232). No desenrolar dessa pequena análise aqui posta, constatamos que o sentido no domínio semiótico é um sentido inerente à língua e que deve ser reconhecido, uma vez que significa. Já no domínio semântico, esse sentido está fora da língua, porque pressupõe sempre uma nova utilização desse sistema de signos, realizada por um enunciador em um aqui e agora únicos; sendo assim deve ser compreendido, uma vez que comunica. Nesse sentido nos damos conta de que é somente pelo funcionamento semântico da língua, segundo Benveniste (2006), que conseguimos vislumbrar a relação linguagem/mundo e que percebemos o elo que une o homem a sua capacidade de colocar a língua em funcionamento e, então, enunciarse.

Essa pequena amostra de análise, sabemos muito inconclusa, exemplifica as palavras de Benveniste (2006:233): “Esses dois sistemas se superpõem assim na língua tal como a utilizamos". E é essa língua em uso que coloca o homem falando com outro homem na sociedade, hoje, produzindo sentidos outros que fazem dele(s) sujeito(s) - ou não - de sua própria enunciação.

\section{CONSIDERAÇÕES FINAIS}

Este estudo teve como principal discussão o problema da significação na língua, levando em considerando os aspectos pertinentes aos domínios semiótico e semântico da língua que, como vimos, funcionam de maneiras diferentes no processo de construção dos sentidos. Nosso principal objetivo era analisar a maneira como os domínios do semiótico e do semântico funcionam no processo de significação da linguagem. Para isso, lançamos mão de três recortes do livro intitulado Todo dia a mesma noite, de Daniela Arbex, que nos deram subsídios para pensar como a leitura da significação se dá tanto na esfera semiótica quanto semântica.

No desenvolvimento da análise pudemos constatar que, enquanto no nível semiótico os sentidos se restringem à língua, no nível semântico esse limite é extrapolado, já que o que importa é o que está fora da língua, que afetará diretamente os sentidos produzidos. Nesse ínterim, nosso foco analítico decaiu, principalmente, sobre a unidade Kiss, que ora era analisada como signo, ora analisada como palavra. Em uma comparação dos três enunciados que compunham o corpus de análise, observamos como os sentidos construíram-se de maneiras diferentes, por conta do presente da enunciação, sempre único, e também constatamos que uma só palavra, tendo em vista o domínio semântico, é capaz de abarcar vários sentidos que se somam e, ao mesmo tempo, se resumem em uma só unidade linguística.

Esta reflexão pode ser considerada uma tentativa de observarmos, na prática, os diferentes modos de ser língua, levando em consideração que a língua é a atividade significante por excelência. Debruçar-se sobre a teoria de Benveniste é sempre um desafio, que nos leva a pensar esse sistema de signos, que é a língua, de forma única. Quando tratamos de enunciação, nos termos de Benveniste, também pressupomos um olhar para o homem em sociedade, ou seja, para nós mesmos, na tentativa de entender de que maneira a língua nos constitui como sujeitos em nossas práticas enunciativas, em nossas vidas.

As considerações desse trabalho são apenas um pequeno vislumbre daquilo que a língua é capaz. Por ser parte essencial daquilo que nos constitui como seres humanos, a língua/linguagem parece oferecer um mar de possibilidades diferentes, principalmente por ser o reflexo de nossas práticas sociais, culturais, morais, entre outras que, por sua vez, estão em constante processo de mutação. Sem sombra de dúvida, o homem está na língua. 


\section{REFERÊNCIAS}

ARBEX, D. Todo dia a mesma noite. Rio de Janeiro: Intrínseca, 2018.

BENVENISTE, É. A forma e o sentido na linguagem. In:

. Problemas de linguística geral II. São Paulo: Pontes, 2006, p. 220-242.

FLORES, V. N. Introducão à teoria enunciativa de Benveniste. São Paulo: Parábola, 2013.

SAUSSURE, F. Curso de linguistica geral. São Paulo: Cultrix, 2006.

Recebido em: 07/09/2020

Aprovado em: 17/10/2020

https://periodicos.unifap.br/index.php/letras

Macapá, v. 10, n. 1, $1^{\mathrm{O}}$ sem., 2020 